\title{
What is hippotherapy? The indications and effectiveness of hippotherapy
}

\author{
Tuba Tulay Koca, ${ }^{1}$ Hilmi Ataseven ${ }^{2}$ \\ ${ }^{1}$ Department of Physical Medicine and Rehabilitation, Malatya State Hospital, Malatya, Turkey \\ 2Public Hospitals Union, Malatya, Turkey
}

\begin{abstract}
Hippotherapy is a form of physical, occupational and speech therapy in which a therapist uses the characteristic movements of a horse to provide carefully graded motor and sensory input. A foundation is established to improve neurological function and sensory processing, which can be generalized to a wide range of daily activities. Unlike therapeutic horseback riding (where specific riding skills are taught), the movement of the horse is a means to a treatment goal when utilizing hippotherapy as a treatment strategy. Hippotherapy has been used to treat patients with neurological or other disabilities, such as autism, cerebral palsy, arthritis, multiple sclerosis, head injury, stroke, spinal cord injury, behavioral disorders and psychiatric disorders. The effectiveness of hippotherapy for many of these indications is unclear, and more research has been needed. Here, we purpose to give information about hippotherapy which is not known adequately by many clinicians and health workers.
\end{abstract}

Key words: Equine-assisted therapy; hippotherapy; therapeutic horse back riding.

$\mathrm{H}$ ippotherapy is a physical, occupational, and speech therapy that utilizes the natural gait and movement of a horse to provide motor, and sensory input. It is based on improvement of neurologic functions, and sensory processes, and used for patients with physical, and mental disorders. Especially, in paralyzed individuals it contributes to physical rehabilitation programs $[1,2]$.

Herein, we wanted to provide information about hippotherapy whose effectiveness has been demonstrated in scientific studies, and so prevalently used in many countries in the fields of physical, and mental disabilities. In our study, recognition of the importance of this new method for our country will provide benefit for many patient groups.

\section{Diagnosis}

Hippotherapy means treatment with the aid of a horse. Despite long-term use in history, only a few studies have been performed on its theoretical basis. Only scarce information are available on its psychological, physical, social, and educational effects in specially trained children. Hippotherapy is a treatment method with concurrently favourable psy- 
chological, social, and educational effects on many organ systems including sensory, musculoskeletal, limbic, vestibular, and ocular systems $[3,4,5]$.

\section{History, and hippotherapy in the world}

Hippotherapy consists of the words meaning "horse" "hippos", and "treatment" "therapy" in ancient Greek. It is defined as equine-assisted treatment. Firstly, it was mentioned in the works of Hippocrates. However, it has not become a discipline with an established protocol up to 1960s. During 1960 s, it is used as an adjunct to traditional physical therapy in Germany, Austria, and Sweeden. In countries as Germany, Austria, and Sweeden which used the horse in physical therapy the term "hippotherapy" was introduced into medical literature. During 1970s in the United States of America (USA ), hippotherapy was started to be standardized $[1,2,3,6]$.

It was standardized by a group of Canadian, and American therapists who traveled to Germany in order to learn hippotherapy near the end of 1980s. American Hippotherapy Association (AHA) was founded in the year 1992, and established an official, and international protocol. In the year 1994 certification document, and standards for certified hippotherapy clinical specialist (HPSC) were established, and in 1999 the first certification examination was realized. This certification program consists of three steps, and encompasses a training period of 3 years $[1,6]$.

With certification program bestowed by American Hippotherapy Association hippotherapist assumes the title of hippotherapy clinical specialist (HPSC). These specialists have knowledge, and experience about hippotherapy. The physiotherapist who received 6000 hours of training, and 100 hours of practical application for at least 3 years, occupational therapist, speech and language specialist deserve to be in this team [1].

In the world, many states in the USA, Seul province in Southern Korea are providing their services in colloboration with AHA. In many European countries as Germany, Belgium, Netherlands, Greece, and Sweeden hippotherapy is covered by general health insurance $[1,6,7]$.

In our country, scarce number of centers provide only limited service. Besides, these patients receive a nonstandardized, and uncontrolled treatment procedure. In our country, hippotherapy is not covered by general health insurance. Every year, many hippotherapy centers are inaugurated by The Ministry of Health, Agriculture and Livestock. With increasing number of the centers which provide certified hippotherapy training, and coverage of hippotherapy sessions with general health insurance, it will be possible to offer effective, safe, and reliable services to patients.

\section{Why are horses are used?}

1. During ambulation the horse provides a rhytmic movement which stimulates anterior, and posterior swinging movements

2. Movements of the horse encourage the rider to achieve a proper balance, and posture

3. The horse, and those around provide the rider a large spectrum of sensory, and motor input $[5,6,7]$.

Horseback riding provide effective, and sensory stimulation for its rider through variable, rhytmic, and repetitive movements of the horse. The movement of the horse mimics the normal movements of the human pelvis during walking. Variations in horse gait enable therapist to measure sensory stimulation, and integrate these measurements with clinical therapies so as to arrive at desired outcomes [7].

Hippotherapy shortens recovery times, and improves balance and muscle control of the patient. Slow, and rhytmic movements of the horse's body have therapeutic values, and ensure development of paraspinal muscles. Multifaceted swinging rhythm of a horse gait effects the bones of patient's pelvic girdle twice more strongly than the gait of a patient. The patients are responding to this entertaining treatment modality with greater compliance, and enthusiasm. Thus, hippotherapy improves balance, mobility, and posture $[7,4]$.

\section{Mechanism of action of hippotherapy}

Physical, and educational therapists have used the movements of the horse for the cure of the patient, while psychologists, and mental health therapists benefit from the horse's mobility so as to achieve or increase compliance of the patients $[1,3,5]$.

Horse pelvis, just like the human pelvis displays a 3-axial movement pattern while walking. Horse 
gait has been carefully graded at every step of the patient's treatment. These variable rhytmic, and repetitive movements provides physical, and sensory feedback to the patient. Favourable physical effects of equine-assisted therapy on coordination, muscle tonus, postural balance, stiffness, flexibility, endurance, strength, correction of abnormal movement pattern, and improvement of gait, and balance have been demonstrated in many studies $[7,4,8,9,3]$.

Mechanism of action of hypotherapy can be divided into four main groups. The first one is core connection. As we know, during daily living performance, balance, lying supine, and walking, postural control, and core connection are very important. Besides, one of the many beneficial effects of hippotherapy is its favourable effect on postural control, and core body connection. During hippotherapy sessions, during horse riding direct contact with patient's pelvis, and spine is ensured. Movements of the horse provide sensory input, and induce motor responses in pelvis, and trunk. Other mechanisms of action of hippotherapy can be enumerated as sensory connection, communication connection, and neuroconnection $[1,10,11,8,9]$.

Hippotherapy has favourable effects on different domains as physical, social, cognitive, psychologic fields, learning, and adaptive behaviours.

\section{Hippotherapy team}

Hippotherapy team consists of a therapist, horse trainer, and riding instructors walking on both sides of the horse. Hippotherapy is applied in the presence of an experienced physiotherapist, horse, and horse carer. Physiotherapist controls the horse gait, gait velocity, and orients the horse into various directions, and all these movements induce neuromuscular, and sensory reactions in the patient. $[7,10,8,9]$.

\section{Indications of hippotherapy}

Hippotherapy can be used in different indications as cerebral palsy $[12,13,14,15,16]$, traumatic brain damage $[2,3]$, Down syndrome, autistic behavioural disorders $[17,18]$, muscular dystrophy, amputated patients, cerebrovascular disease (SVD) $[19,20]$, multiple sclerosis $[3,21]$, psychiatric diseases $[14,15,16]$, spinal cord diseases, and rheumatismal joint diseases etc.

\section{Hippotherapy as a physical therapy}

In physical therapy, multidirectional movements of the horse are utilized in gait training, balance, postural control, strengthening, and increasing range of motion. In many studies, improvements in gross motor skills, and functional activities have been reported in disabled children $[4,6,7,22,10]$.

\section{Hippotherapy as ocupational therapy}

In occupational therapy, movements of the horse are utilized with the intention to improve motor control, coordination, balance, attention, sensory processes, and performance in daily activities. Sensory processes, vestibular, proprioceptive, tactile, visual, and auditory systems are targeted simultaneously $[4,6,7]$.

\section{Hippotherapy as speech, and language therapy}

Hippotherapy also targets improvements in speech, language, cognitive, and masticatory functions $[4,6,7]$.

\section{Scientific clinical studies performed concerning hippotherapy}

Hippotherapy provides sensory feedback by utilizing movements of the horse, and thanks to this characteristic its used in diverse neurological conditions. Multiple sclerosis (MS) affects multiple number of neurological processes leading to disorders of postural balance [21]. Munoz-Lasa et al. compared hippotherapy, traditional physical therapy on 27 patients with MS, and observed marked improvements in performance-oriented mobility assessment scores, and two gait parametres (jump time, and ground reaction force) [21]. They concluded that in ambulatory MS patients hippotherapy can improve postural balance, and gait. In their Internet-based home-training program, Frevel D et al. [23] investigated the effect of hippotherapy on the postural balance of MS patients, and applied twice weekly hippotherapy sessions $(n=9)$ or Internetbased home therapy $(n=9)$ for 12 weeks, and investigated static, and dynamic balance capacity in both groups. They observed comparable effects of both methods on postural balance, while in the hippotherapy group they noted marked improvement in fatigueness, and quality of life [23].

In a study by Lee CW et al. [19] on 36 patients with $\mathrm{CVO}$, the patients were subjected to a pro- 
gram lasting for 8 weeks. The first group received hippotherapy, while the second group practiced treadmill exercises. In the first group, significant improvements of gait parametres as pace, and length of stride, asymmetry rate, while Berg balance scores were not significantly different [19]. In a similar study performed by Kim SG et al. [20] on elder patient population, the patients were also divided into hippotherapy, and treadmill groups. At the end of the study, increase in stride length, and decrease in stride time, and period of swinging (shorter in the hippotherapy group) were seen in both groups. The authors concluded that hippotherapy can improve static balance, and gait in elder population [20].

Parents of many autistic children included in the hippotherapy program observe marked improvements in physical, social, and sensory functions of their children. Hippotherapy effects behaviours of autistic children favourably [17]. Aizenman F et al. applied twice weekly hippotherapy sessions on 6 autistic children aged between 5-12 years for 12 weeks, and evaluated Vineland adaptive behaviour scale II, and Activity Card Measurements before, and after treatment [18]. At the end of the study marked decrease in postural swing, and increases in all adaptive behaviours (communication, copying), self-care, light activities, and social interaction were observed. At the end of the study, favourable effects of hippotherapy on these pediatric population were seen. Hippotherapy can be one of the complementary treatment strategies in autistic children.

In children with cerebral palsy (SP) exercisebased therapies aimed at improving postural control have been used more frequently during the last decade $[22,10]$. In many studies, the authors have concluded that hippotherapy improved balance, and postural control. Park ES et al. [24] investigated the effect of hippotherapy on gross motor functions, and functional performance in children with SP (15 male, and 19 female children, aged 3-12 years), and applied twice weekly hippotherapy programs for 8 weeks each session lasting for 45 minutes, and measurements were based on gross Motor Function Measurement Scale -66, And 88 (GMFM), and Pediatric Functional Skill Scale (PEDI-FSS) [24]. Parametres before hippotherapy were comparable between groups, while at the end of the study mean GMFM-66, and 88 scores improved markedly (be- ing more prominent in the hippotherapy group). When compared with the control group, PEDIFSS scores improved predominantly in the hippotherapy group.

In conclusion, hippotherapy can be beneficial in maximizing functional performance in children with SP. Kwon JY [25] randomized 96 patients with SP aged 4-10 years into 2 groups, and the first group received twice weekly hippotherapy sessions each lasting for 30 minutes for a period of 8 weeks, and the results were evaluated based on Gross Motor Function Classification System -66, and 88, and Pediatric Postural Balance Scale [25]. At the end of the study marked improvement was detected in the hippotherapy group as evaluated using GMFCS-88 scale. We can say that hippotherapy exerts favourable effects on gross motor functions, and postural balance of children with SP at various functional levels $[24,25,26]$. In a literature screening performed by Sterba JA'nin [12] on the effectiveness of hippotherapy on gross motor functions in children with SP, the authors had found 11 articles published on effectiveness of hippotherapy in SP: Hippotherapy is effective in the treatment of trunk, and hip asymmetry, and it also improves gross motor functions when compared with classical treatment modalities $[26,12]$. Ş1k B et al. performed a study on a total of 20 patients with SP, and observed a statistically significant favourable effect of hippotherapy on gross motor functions, and balance coordination when compared with the control group [13].

Animal-assisted psychotherapy used in childhood has attracted attention for years. In cases with chronic diseases, favourable effect of small pet animals on these children is already known. In recent years, in pediatric, and adolescent psychiatry horse or pony-assisted therapy has been an interesting phenomenon which is also encouraged by health professionals $[14,15]$. Guerino et al. investigated the effectiveness of hippotherapy in two young women (18, and 21 years of age, respectively) who were exposed to sexual assault during childhood [16]. They observed serious motor limitation, coordination disorders, conspicuous muscle spasms, and postural disorders as thoracic, and cervical kyphosis, and cervical protrusion in these girls. These two patients had undergone 20 sessions of hippotherapy each lasting for 30 minutes. At the end of the 
therapy, they observed improvements in the posture $(30 \%)$, coordination $(80 \%)$, body balance, sociality, and self-confidence (50\%) at indicated rates.

Among mental diseases, most frequently the patients with eating disorders require multidisciplinary treatment. In these patients effectiveness of equine-assisted psychotherapy has been observed in various studies $[27,28]$.

\section{Conclusion}

Hippotherapy is a treatment modality whose effectivenes has been confirmed in a large patient group with physical or mental disabilities when applied by an experienced therapist with the aid of a horse. Equine-asisted therapy is being used widely in many countries of the world. We think that as the importance of hippotherapy is acknowledged more deeply by physicians, and therapists in our country, greater number of patients, and their families will benefit from this form of treatment.

Conflict of Interest: No conflict of interest was declared by the authors.

Financial Disclosure: The authors declared that this study has received no financial support.

\section{REFERENCES}

1. Meregillano G. Hippotherapy. Phys Med Rehabil Clin N Am 2004;15:843-54.

2. Benda W, McGibbon NH, Grant KL. Improvements in muscle symmetry in children with cerebral palsy after equineassisted therapy (hippotherapy). J Altern Complement Med 2003;9:817-25.

3. Silkwood-Sherer D, Warmbier H. Effects of hippotherapy on postural stability, in persons with multiple sclerosis: a pilot study. J Neurol Phys Ther 2007;31:77-84.

4. Silkwood-Sherer DJ, Killian CB, Long TM, Martin KS. Hippotherapy-an intervention to habilitate balance deficits in children with movement disorders: a clinical trial. Phys Ther 2012;92:707-17.

5. Champagne D, Dugas C. Improving gross motor function and postural control with hippotherapy in children with Down syndrome: case reports. Physiother Theory Pract 2010;26:564-71.

6. Debuse D, Chandler C, Gibb C. An exploration of German and British physiotherapists' views on the effects of hippotherapy and their measurement. Physiother Theory Pract 2005;21:219-42.

7. Meregillano G. Hippotherapy. Phys Med Rehabil Clin N Am 2004;15:843-54.
8. Shurtleff TL, Engsberg JR. Changes in trunk and head stability in children with cerebral palsy after hippotherapy: a pilot study. Phys Occup Ther Pediatr 2010;30:150-63.

9. Shurtleff TL, Standeven JW, Engsberg JR. Changes in dynamic trunk/head stability and functional reach after hippotherapy. Arch Phys Med Rehabil 2009;90:1185-95.

10. Zadnikar M, Kastrin A. Effects of hippotherapy and therapeutic horseback riding on postural control or balance in children with cerebral palsy: a meta-analysis. Dev Med Child Neurol 2011;53:684-91.

11. Rigby BR, Grandjean PW. The Efficacy of Equine-Assisted Activities and Therapies on Improving Physical Function. J Altern Complement Med 2016;22:9-24.

12. Sterba JA. Does horseback riding therapy or therapist-directed hippotherapy rehabilitate children with cerebral palsy? Dev Med Child Neurol 2007;49:68-73.

13. Yıldırım Şık B, Çekmece C, Dursun N, Dursun E, Balıkçı E, Altunkanat Z, et al. Is Hyppotherapy Beneficial for Rehabilitation of Children with Cerebral Palsy? Türk Klin J Med Sci 2012;32:601-8.

14. Masini A. Equine-assisted psychotherapy in clinical practice. J Psychosoc Nurs Ment Health Serv 2010;48:30-4.

15. Quint C, Toomey M. Powered saddle and pelvic mobility: an investigation into the effects on pelvic mobility of children with $\mathrm{CP}$ of a powered saddle which imitates the movements of a walkinghorse. Physiother 1998;84:376-84.

16. Guerino MR, Briel AF, Araújo Md. Hippotherapy as a treatment for socialization after sexual abuse and emotional stress. J Phys Ther Sci 2015;27:959-62.

17. Muslu GK, Conk H. Animal-Assisted Interventions and Their Practice in Children. Duehyo ED 2011;4:83-8.

18. Ajzenman HF, Standeven JW, Shurtleff TL. Effect of hippotherapy on motor control, adaptive behaviors, and participation in children with autism spectrum disorder: a pilot study. Am J Occup Ther 2013;67:653-63.

19. Lee CW, Kim SG, Yong MS. Effects of hippotherapy on recovery of gait and balance ability in patients with stroke.J Phys Ther Sci 2014;26(2):309-11.

20. Kim SG, Lee CW. The effects of hippotherapy on elderly persons' static balance and gait. J Phys Ther Sci 2014;26:25-7.

21. Muñoz-Lasa S, Ferriero G, Valero R, Gomez-Muñiz F, Rabini A, Varela E. Effect of therapeutic horseback riding on balance and gait of people with multiple sclerosis. G Ital Med Lav Ergon 2011;33:462-7.

22. Snider L, Korner-Bitensky N, Kammann C, Warner S, Saleh M. Horseback riding as therapy for children with cerebral palsy: is there evidence of its effectiveness? Phys Occup Ther Pediatr 2007;27:5-23.

23. Frevel D, Mäurer M. Internet-based home training is capable to improve balance in multiple sclerosis: a randomized controlled trial. Eur J Phys Rehabil Med 2015;51:23-30.

24. Park ES, Rha DW, Shin JS, Kim S, Jung S. Effects of hippotherapy on gross motor function and functional performance of 
children with cerebral palsy. Yonsei Med J 2014;55:1736-42.

25. Kwon JY, Chang HJ, Yi SH, Lee JY, Shin HY, Kim YH. Effect of hippotherapy on gross motor function in children with cerebral palsy: a randomized controlled trial. J Altern Complement Med 2015;21:15-21.

26. Benda W, McGibbon NH, Grant KL. Improvements in muscle symmetry in children with cerebral palsy after equineassisted therapy (hippotherapy). J Altern Complement Med
2003;9:817-25.

27. Granados AC, Agís IF. Why children with special needs feel better with hippotherapy sessions: a conceptual review. J Altern Complement Med 2011;17:191-7.

28. Casady RL, Nichols-Larsen DS. The effect of hippotherapy on ten children with cerebral palsy. Pediatr Phys Ther 2004;16:16572. 